\title{
A aplicação das Leis 10.639/03 e 11.645/08 na educação das relações étnico-raciais
}

\author{
DOI: 10.47224/revista master.v6i11.158
}

\author{
Danilo Faria de Moura \\ Maria Luiza de Borba Alves \\ Beatriz Carolina Ferreira \\ Fernanda Leticia Leite Borges \\ Josiele Moreira Cândido \\ Oséias Carneiro Amorim \\ Thais Rodrigues Pereira
}

e-mail: danilofmoura@yahoo.com.br

\section{Resumo}

O presente estudo buscou alinhar e engajar todos os envolvidos no processo educativo para uma verdadeira concretização das leis 10.639/03 e 11.645/08, na perspectiva de cumprimento do que essas asseguram, além de explorar a realidade das práticas escolares conhecendo um pouco mais da interação: família, escola e a comunidade e atuação desses diante das leis em questão. A pesquisa foi norteada pela Metodologia da Problematização do Arco de Maguerez, seguindo o eixo temático: indagações acerca das práticas docentes relacionadas a cultura afro-brasileira no ensino fundamental em instituições públicas e privadas da cidade de Araguari/MG. O aporte teórico se deu por meio de uma pesquisa bibliográfica para o embasamento dos assuntos apresentados. As observações foram realizadas por meio de formulários online, com professores de áreas, considerou-se, assim, as práticas exercidas nas inúmeras áreas da educação. Como resultado alcançado, deseja-se uma maior visibilidade para as leis supracitadas, assim como um melhor engajamento da família e uma comunidade inteirada ao assunto, que muitas vezes é desamparada e ainda na pior das hipóteses emudecido.

Palavras-chave: Lei 10.639/03; Lei 11.645/08; Família, Escola e Comunidade.

Abstract

This study sought to align and have interaction all those involved within the educational process for a real implementation of laws $10.639 / 03$ and $11.645 / 08$, within the perspective of compliance with what they ensure, additionally to exploring the truth of faculty practices knowing a touch more about the interaction: family, school and community and modern practice of the laws in question. The research was guided by the Methodology of Problematization of Arco de Maguerez, following the thematic axis: questions on teaching practices associated with Afro-Brazilian culture in education publicly and personal institutions within the city of Araguari/MG. The theoretical contribution was made through a bibliographical research for the idea of the addressed subjects. As wasted was administered through online forms, with area teachers, it had been considered, thus, the practices exercised within the education areas. As a result, greater visibility for the laws is desired, also as a far better engagement of the family and a community fully conscious of the difficulty, which is usually helpless and even at the worst muted.

Keywords: $\quad$ Law 10.639/03; Law 11645/08; Family, School and Community.

\section{INTRODUÇÃO}

Para Pereira (2011, p. 149) não é possível prever a forma como uma legislação será recebida e praticada. A autora afirma ainda que: "todos sabemos o que há de ressonância - ou de distância entre o conteúdo de uma lei e a sua prática nas mais variadas circunstâncias, sobretudo no ambiente escolar."

Nessa perspectiva, acompanhar e ter conhecimento acerca da legislação não se restringe somente às instituições de ensinos seus envolvidos diretamente, mas é também dever dos pais e da 
comunidade buscar, fomentar e colocar em prática essas informações.

Objetivando a promoção da igualdade étnico-racial, a Resolução no 1 do Conselho Nacional de Educação, 7 de junho de 2004, direciona em seu Artigo 20 que:

Art. 2- As Diretrizes Curriculares Nacionais para a Educação das Relações Étnicos Raciais e para o Ensino de História e Cultura Afro-Brasileira e Africanas constituem-se de orientações, princípios e fundamentos para o planejamento, execução e avaliação da Educação, e têm por meta promover a educação de cidadãos atuantes e conscientes no seio da sociedade multicultural e pluriétnica do Brasil, buscando relações étnico-sociais positivas, rumo à construção de nação democrática.

§1ㅇ A Educação das Relações Étnico-Raciais tem por objetivo a divulgação de conhecimentos, bem como de atitudes, posturas e valores que eduquem cidadãos quanto à pluralidade étnico-racial, tornando-as capazes de interagir e de negociar objetivos comuns que garantam, a todos, respeito aos direitos legais e valorização de identidade, na busca da consolidação da democracia brasileira.

$\S 2$ 2 O Ensino de História e Cultura AfroBrasileira e Africana tem por objetivo o reconhecimento e valorização da identidade, história e cultura dos AfroBrasileiros, bem como a garantia de reconhecimento e igualdade de valorização das raízes africanas da nação brasileira, ao lado das indígenas, europeias, asiáticas (BRASIL, 2004).

Assim, nota-se a garantia instituída por meio das DCNs (Diretrizes Curriculares Nacionais) na promoção e valorização da cultura Afro-Brasileira.

O estudo em questão foi desenvolvido por discentes do Curso de Pedagogia, junto ao componente curricular "Projeto Integrador VII - Educação das Relações Étnicos-Raciais e História e Cultura AfroBrasileira, Africana e Indígena", correspondentes ao sexto e sétimos períodos, no primeiro semestre de 2020.

As informações foram coletadas mediante utilização da ferramenta de pesquisa Google Formulários, aplicados com a finalidade de levantar informações da atual realidade referentes ao cumprimento das Leis 10.639/03 e 11.645/08. A pesquisa foi norteada pela Metodologia da Problematização do Arco de
Maguerez, seguindo o eixo temático: indagações acerca das práticas docentes relacionadas a cultura afro-brasileira no ensino fundamental em instituições públicas e privadas da cidade de Araguari/MG. $\mathrm{O}$ aporte teórico se deu por meio de uma pesquisa bibliográfica para o embasamento dos assuntos apresentados.

Os professores responderam ao questionário relacionado à problemática, direcionando a observação da realidade e gerando fundamentos e assuntos a serem abordados.

As Proposições Curriculares para Educação Infantil de Belo Horizonte (2016, p. 59), definem que: "escola e família são âmbitos separados que precisam coexistir e complementarem-se durante um período significativo da vida de crianças e adolescentes." Diante disso, evidencia-se que é de suma importância alinhar família, escola e comunidade na concretização de uma aprendizagem plena e significativa, principalmente contemplando os direitos e deveres instituídos pela legislação.

A finalidade geral do presente estudo é questionar e pesquisar acerca do cumprimento da LDB (Lei de Diretrizes e Bases da Educação) no âmbito "História e Cultura Afro-Brasileira", enfatizando as Leis $10.639 / 03$ e $11.645 / 08$. Tem-se por especificidade dos objetivos, discorrer sobre as práticas docentes durante o ano letivo, as quais compreendam a execução, por excelência, dos direcionamentos legislativos, propondo novos olhares e caminhos que visem uma reflexão minuciosa na busca por uma educação mais equânime que alcance todos os alunos, sem distinção.

O problema está em consonância com a finalidade geral, tendo papel de ampliar e orientar a centralidade da pesquisa a fim de sua explanação. Dentre os objetivos específicos encontram-se os detalhes do objetivo em geral, apresentando caráter mais palpável cuja função é mediar, propiciando aos lados, geral e específico, a alcançarem suas finalidades.

Posterior a introdução será apresentado a observação da realidade, em seguida as justificativas, a delimitação da problemática, os pontos-chave, o desenvolvimento partindo da teorização, as hipóteses de solução e considerações finais. 
2

\section{OBSERVAÇÃO DA REALIDADE}

"Há possibilidades para diferentes amanhãs. A luta já não se reduz a retardar o que virá ou a assegurar a sua chegada; é preciso reinventar o mundo. A educação é indispensável nessa reinvenção." (FREIRE, 2006, p.40 apud COELHO; CONSTANTINO; MOREIRA, 2012, p. 10).

A luta pela educação é constante, afastar a insegurança que faz parte do ambiente escolar deve uma das prioridades educacionais. A extinção do preconceito é um caminho árduo e doloroso, porém possível. Essa luta terá uma grande conquista com a ajuda da escola e o apoio da sociedade. Os pequenos passos caminhados e as vitórias vindouras, serão muito benéficas para a comunidade, uma vez que esta se baseie em uma educação equânime.

Devido ao cenário da pandemia de Coronavírus (COVID-19), e as determinações da Organização Mundial da Saúde (OMS) que sugerem o isolamento social, não foi possível a realização das observações da realidade presencialmente. Para o levantamento das questões a serem analisadas, utilizou-se como instrumento de apoio para conhecer a adesão das instituições educacionais às Lei 10.639/03 e 11.645/08. Aplicou-se o "Questionário - Educação das Relações Étnico-raciais e história e cultura afrobrasileira, africana e indígena", por meio da ferramenta digital Google Formulários, de forma online, enviado à professores de inúmeras escolas da comarca de Araguari via aplicativo WhatsApp. A coleta de dados se deu entre dias 05 e 11 de maio de 2020, sendo recebidas 09 (nove) respostas. As participações foram anônimas e será mantido o sigilo durante todo o processo de análise de dados e elaboração deste estudo.

Perfil dos profissionais questionados:

\section{Faixa etária:}

- 05 entre 20 e 35 anos (55\%);

- 03 entre 36 e 50 anos (33\%);

- 0 entre 51 e 65 anos (0\%);

- 01 acima de 60 anos (12\%);

Sexo:

- 08 feminino (88\%);

- 01 masculino (12\%).

Nível de formação:
- 02 graduação $(22,5 \%)$;

- 05 especialização (55\%);

- 02 mestrado (22,5\%);

- 0 doutorado (0\%).

\section{Atuação em instituições educacionais de que segmento:}

- 02 públicas Municipais (22,5\%);

- 05 públicas Estaduais (55\%);

- 0 públicas Federais (0\%);

- 0 públicas Assistenciais (0\%);

- 02 instituições Privadas/particulares (22,5\%).

As questões respondidas pelos entrevistados apresentaram os seguintes resultados:

Em sua escola como é o Material de Apoio? Existe no acervo escolar muitos e variados materiais didáticos, livros, brinquedos, vídeos que contemplem as questões raciais e os conteúdos da História da África, dos Afrobrasileiros e indígenas disponíveis para uso dos estudantes e educadores?

- Consolidado/Realizado: $44,4 \%$

- Em desenvolvimento: 44,4\%

- Não iniciado: $11,2 \%$

Representa-se a diversidade sociocultural e racial brasileira com brinquedos, vídeos, filmes e imagens positivas nos cartazes, murais, painéis e produções gráficas pedagógicas da rotina escolar?

- Consolidado/Realizado: $66,7 \%$

- Em desenvolvimento: 22,1\%

- Não iniciado: $11,2 \%$

Possui acervo, promove estudos e socializa publicações, cursos, documentos e legislações relativas à implementação das Leis 10.639/03 e 11.645/08, junto aos(às) seus(suas) profissionais?

- Consolidado/Realizado: 11,2\% 
- Em desenvolvimento: $44,4 \%$

- Não iniciado: $44,4 \%$

Em sua escola como são os diálogos com as famílias e comunidade e ambas participam das ações de implementação das Leis $10.639 / 03$ e $11.645 / 08$ ?

- Consolidado/Realizado: $44,4 \%$

- Em desenvolvimento: $44,4 \%$

- Não iniciado: $11,2 \%$

As famílias se envolvem nas atividades relacionadas a valorização da cultura negra e indígena, promovidas pela escola?

- Consolidado/Realizado: $44,4 \%$

- Em desenvolvimento: 44,4\%

- Não iniciado: $11,2 \%$

Toda a comunidade escolar já foi esclarecida sobre os propósitos das Leis 10.639/03 e $11.645 / 08$ e como elas serão trabalhadas no cotidiano escolar?

- Consolidado/Realizado: $44,4 \%$

- Em desenvolvimento: 27,8\%

- Não iniciado: $27,8 \%$

Existe proposta de trabalho pedagógico para diminuir o uso de apelidos depreciativos para negros e outros grupos socialmente discriminados no ambiente escolar?

- Consolidado/Realizado: $77,8 \%$

- Em desenvolvimento: 11,1\%

- Não iniciado: $11,1 \%$

A escola possui estratégias pedagogicamente estabelecidas, para acolhimento tanto dos(as) estudantes discriminados(as) como dos discriminadores(as)?

- Consolidado/Realizado: $77,8 \%$

- Em desenvolvimento: $11,1 \%$
- Não iniciado: 11,1\%

A escola investe na formação continuada para os educadores(as)?

- Consolidado/Realizado: 0\%

- Em desenvolvimento: 55,6\%

- Não iniciado: $44,4 \%$

A escola possui um protocolo, construído coletivamente com a comunidade escolar que define institucionalmente os procedimentos a serem adotados na ocorrência de situações discriminatórias e racistas?

- Consolidado/Realizado: $22,2 \%$

- Em desenvolvimento: 66,7\%

- Não iniciado: $11,1 \%$

As atenções se voltam primordialmente para os resultados que apontaram as principais deficiências no que diz respeito ao pleno cumprimento e efetivação das Leis 10.639/03 e 11.645/08.

\section{JUSTIFICATIVA}

O meio escolar deve apoiar-se nas diferenças como instrumento de aprendizagem, pois, somente assim "deixaremos de tratar as diferenças socioculturais como estranhas e folclóricas [...]" (SILVA, 2012 p. 42). Contudo, a escola e seus envolvidos devem apropriar-se de mecanismos que coloquem em pauta as diferenças e diversidades como potencializadores do ensino e da aprendizagem, embasando-se na legislação que atribuía à formação acadêmica questões que ainda não são plenamente aceitas, conhecidas e desenvolvidas.

Este estudo se justifica tendo por base a deficiência que algumas instituições de ensino apresentaram no cumprimento do que é proposto pela LDB (Lei de Diretrizes e Bases da Educação Nacional), e as Leis $10.639 / 03$ e 11.645/08. Constatou-se essa deficiência por meio da pesquisa efetuada.

É de suma importância enfatizar que a condição dos indígenas no Brasil atualmente é extremamente séria, além de ainda lidarem com o preconceito 
enraizado, sofrem com a negação de seus direitos e, ainda, a proteção que lhes perdurava de um longo período está ameaçada. Isso se torna mais evidente através da fala de um líder indígena:

O branco, o caraíba, está maltratando esse rio Xingu. Todas as cabeceiras estão sendo desmatadas, estão botando muita coisa que a gente não gosta, tem muito boi cagando no rio e o pior, estão jogando muito veneno na água que vem parar aqui" acrescentando que há menos peixe nos rios, o gosto dos peixes está diferente, os macacos estão magros, a água está ruim. (RICARDO et al, 2006, p. 28-29).

Nessa perspectiva, nota-se o desrespeito com a população e povos que habitam essas terras desde a colonização, tornando-se algo ainda mais grave: racismo. Racismo com os povos indígenas e racismo com os afrodescendentes. Existem outras esferas de racismo, entretanto, somente essas duas serão tratadas no presente projeto.

No Brasil, em 5 de janeiro de 1989 foi homologada a Lei $7.716 / 89$, que trata o racismo como crime. Segundo Xavier e Xavier (2002):

A ciência do século XIX esculpiu os contornos delimitadores do perfil dos africanos e dos afrodescendentes, escravizados e marginalizados do sistema de bem-estar social. Essa ciência editou conceitos e preconceitos que procuram justificar a escravidão, o etnocídio e a exclusão social (XAVIER; XAVIER, 2002, p. 109).

Devido essa estereotipação do perfil dos negros, alguns professores se equivocam e reproduzem ideologias carregadas de estigmas para seus alunos acerca da história da colonização. Diante dessa situação equivocada, surge a necessidade de desenvolver essa temática nas escolas com uma proposta mais reflexiva e pautada na ótica do negro, afrodescendente e do índio.

\section{DELIMITAÇÃO DO PROBLEMA}

Sobre a determinação acerca dos estudos que envolvem toda a história e cultura africana e afrobrasileira, por meio das Leis 10.639/03 e 11.645/08,
Jesus (2015, p. 4) alega que "não foi uma benesse do governo brasileiro, mas sim, uma luta da população negra".

Nessa perspectiva, percebemos os desafios do reconhecimento e da necessidade de se trabalhar durante todo o ano letivo essa temática nas escolas. Anteriormente, o mesmo autor questiona sobre o que, de fato, está sendo feito a este respeito aos tantos que se encontram cansados de ouvir falar das Leis $10.639 / 03$ e $11.645 / 08$ ? Ou seja, muitos conhecem a legislação, sabem de sua existência, porém, fazem vista grossa, não possuem ações compatíveis e não se atentam em inseri-las no calendário acadêmico, de forma que perdure por todo o ano letivo.

Com a aplicação do formulário, constatou-se algumas irregularidades em alguns pontos no que tange a atender as normas das diretrizes governamentais. Dentre elas destacam-se:

- Questão número 6: Em sua Escola, como é o material de apoio? Existe no acervo escolar, muitos e variados materiais didáticos, livros, brinquedos vídeos que contemplem as questões raciais e os conteúdos da História da África e dos afrobrasileiros e indígenas, disponíveis para uso dos estudantes e educadores?

- Questão número 6.3: Representa-se a diversidade sociocultural e racial brasileira com brinquedos, vídeos, filmes e imagens positivas nos cartazes, murais painéis e produções gráficas pedagógicas da rotina escolar?

- Questão número 7: Em sua Escola, como são os diálogos com as famílias e comunidade? As famílias e toda a comunidade escolar participam das ações de implementação das Leis 10.639/03 e 1 $1.645 / 08$ ?

- Questão número 7.5: Toda a comunidade escolar já foi esclarecida sobre os propósitos das Leis 10.639/03 e I I.645/08 e como ela será trabalhada no cotidiano escolar?

- Questão número 8.2: Existe proposta de trabalho pedagógico para diminuir o uso de apelidos depreciativos para negros e outros grupos socialmente discriminados no ambiente escolar? 
Partindo das análises, constatou-se que as problemáticas do presente estudo procuram respostas para o seguinte questionamento:

- Como promover e/ou tornar realidade o diálogo da escola entre as famílias e a comunidade escolar, que tenha por consequência a participação de todos nas ações de implementação das Leis $10.639 / 03$ e $11.645 / 08$ ?

Concomitantemente com esse questionamento, análises serão realizadas, possibilidades serão pontuadas, buscando hipóteses de soluções ao problema aqui mencionado, com o intuito de melhor desenvolver a temática entre todos os envolvidos, fazendo com que ações sejam efetivadas e materializadas, uma vez que nossas instituições de ensino sozinhas não se bastam para efetivação da significativa mudança ou quebra de paradigmas.

\section{5}

\section{PONTOS-CHAVE}

Sobre a Lei $10.639 / 03$, que foi alterada pela Lei $11.645 / 08$, Fortunato $(2014$, p. 50$)$ defende que "já deveria fazer parte da rotina das escolas em todo território nacional". Mesmo passando-se vários anos de homologação da Lei, incluindo sua alteração, não existe uma efetiva implantação de suas diretrizes nas escolas brasileiras, havendo descuido no ambiente escolar.

Alguns fatores ligados ao problema em pauta relacionam-se à falta de conhecimento por parte dos docentes acerca das Leis 10.639/03 e 11.645/08. Evidencia-se, ainda, a carência de materiais didáticos sobre o período de colonização, pautado na ótica afro-brasileira.

Pode-se destacar como maiores fatores condicionantes a estruturação dos calendários escolares sem o adicionamento no cotidiano escolar das atuais legislações que tratam da temática deste estudo, sendo este ainda meramente citado e poucas vezes efetivado na prática. Nota-se, também, a falta de interesse por parte dos pais para inteirar-se das variáveis que circundam e adentram o ambiente escolar. Enfatiza-se, ainda, a não fiscalização e acompanhamento governamental da execução dessas leis.
Refletir sobre os fatores condicionantes permitiu compreender adequadamente os motivos para a presença do problema, tornando possível se deparar com suas particularidades. Tenciona-se que os pontos influenciadores para a presença do problema são:

- Falta de envolvimento das famílias nas atividades relacionadas à valorização da cultura negra e indígena promovidas pela escola;

- Ausência de acervo, cursos, documentose fiscalizações relativas à implementação das Leis 10.639/03 e 11.645/08;

- Inexistência de estratégias pedagogicamente estabelecidas para acolhimento tanto dos) estudantes discriminados como dos discriminadores;

- Carência de materiais didáticos voltados à temática pesquisada;

- Falta de investimento em cursos de formação continuada que abordem a temática voltados aos profissionais da educação.

Partindo dos pontos destacados, procurou-se investigar e aprofundar-se teoricamente tendo por objetivo uma ampla compreensão das questões destacadas.

\section{TEORIZAÇÃO}

O respaldo teórico, que é uma considerável e/ou indispensável ferramenta para o aprofundamento e entendimento quanto aos pontos-chave apresentados e, por consequência leva-se às hipóteses de solução para o problema levantado, do presente estudo, deu-se por meio da leitura de livros disponíveis em bibliotecas virtuais e artigos científicos disponibilizados em plataformas digitais.

Segundo Jesus (2015, p. 2) “a educação, especialmente a escolar, seria a principal estratégia para alterar as desigualdades raciais no Brasil". Essa visão sobre as perspectivas da educação deu-se na década de 90, época marcada por uma árdua luta para expor as consequências do racismo. Porém, segundo o mesmo autor, ainda na época em questão, evidenciou que: 
“[...] já percebiam e denunciavam que a escola reproduz o racismo da/na sociedade, veicula valores preconceituosos e atitudes discriminatórias, que os materiais pedagógicos e, especialmente, os livros didáticos, reproduzem estereótipos sobre o negro, silenciam ou omitem a história e a cultura dos negros no Brasil e na África e, portanto, devem ser revisados". (JESUS, 2015, p. 2)

Infelizmente, essa afirmação constatada há trinta anos, ainda é vivenciada nas escolas. Mesmo com a determinação da Lei 10.639/03 que versa sobre o Ensino da História e Cultura Afrobrasileiro e Africana ressaltando a importância da cultura negra na formação da cultura brasileira, pouca coisa mudou.

A Lei 11.645/08 estabelece a obrigatoriedade da inclusão no currículo oficial da rede de ensino da temática História e Cultura Afro-brasileiro e Indígena, a qual ainda é superficialmente conhecida pelos profissionais da educação, limitando-se ao cumprimento de datas comemorativas estabelecidas em calendários escolares, não incorporando na rotina e nos conteúdos diários. Essa deve ser uma ação trabalhada de forma interdisciplinar visando o esclarecimento de dúvidas e a mudança nas posturas das pessoas quanto a aceitação do negro, afrodescendente e indígena na vida das comunidades.

\subsection{Falta de Participação da Família e Falta de Documentos Sobre a Legislação}

É perceptível que existe falha no envolvimento das famílias nas atividades relacionadas à valorização da cultura negra promovidas pela escola.

De fato, se por um lado, os estudiosos são unânimes em reconhecer a intensificação dos contatos entre as duas instituições, por outro lado encontram-se também frequentes referências às tensões e ambiguidades que permeiam essa relação. (RESENDE; SILVA, 2016, p. 35).

Conforme resultados obtidos através de questionários aplicados aos docentes, ficou em evidência que o número de famílias que não caminham junto à escola no que é proposto ainda é muito grande.
A criação de espaços de diálogos entre estudantes e familiares [...] ampliou em muito a dimensão de contato com diferentes mundos da vida, potencializando as trocas de aprendizagens dada pela interação dos sujeitos. (COELHO; CONSTANTINO; MOREIRA, 2012, p. 6).

Assim, nota-se a necessidade de investimento para a concepção de momentos em que os diálogos intermediados pela escola entre os estudantes e seus familiares se tornem mais do que meros encontros de apontamentos, mas também se efetivem em ações conjuntas a fim de se estabelecer sentido e significado.

Evidenciou-se a não existência de documentos nas escolas que retratem a implementação das leis $10.639 / 03$ e 11.645/08. A não efetivação dessas leis, dá-se pela falta de material de apoio nos acervos e nas bibliotecas. Há muito a se considerar a esse respeito, uma vez que essas leis poderiam ser implantadas de forma lúdica por meio de elaboração de histórias, vídeos e músicas. $\mathrm{Na}$ maioria das vezes a leitura de artigos de lei não são agradáveis e de fácil compreensão, assim, essas acabam ficando engavetadas sendo utilizadas apenas quando necessário.

Ainda, segundo Pereira (2011, p. 156), através de uma pesquisa no campo formativo para a docência um professor relatou "não conhecer obras voltadas à abordagem da história africana, afro-brasileira e indígena na Educação Básica". Essa é uma triste realidade vivenciada por muitos docentes, que necessariamente não conseguem embasar pensamentos e diálogos por falta de referências que se preocupem com esta etapa educacional e de formação. Na maioria das vezes os livros didáticos trazem um conteúdo pobre e limitado no que tange a africanidade e, principalmente, os afrodescendentes.

Nessa perspectiva, é notável a significância da escola conter dentro de seus materiais didáticos e paradidáticos temáticas que abordem a implementação das leis em questão, preferencialmente com o olhar do negro brasileiro. 


\subsection{Falta de Estratégias Pedagógicas no Combate ao Racismo}

Pontuou-se a não existência de estratégias pedagogicamente estabelecidas para acolhimento tanto dos estudantes discriminados como dos discriminadores.

As propostas pedagógicas focadas na Educação de qualidade, participativa, cidadã e transformadora partem do princípio do respeito às diferenças e preveem a construção do conhecimento escolar alicerçado na História crítica e incentivadora à Consciência Histórica da diversidade cultural. (ROCHA et al, 2016, p. 16).

Dessa forma fica claro o papel da escola, no estabelecimento de estratégias de prevenção e reparação de atitudes contrárias às temáticas asseguradas pelas leis 10.639/03 e 11.645/08. Entretanto, são essas estratégias um tanto limitadas, uma vez que não conseguem assegurar êxito no esclarecimento de pontos importantes acerca do respeito e valorização da cultura africana.

É importante saber como se fala, ter a compreensão do que se fala e mais: partir para a ação, para a construção de práticas e estratégias de superação do racismo e da desigualdade racial. Essa é uma tarefa cidadã de toda a sociedade brasileira e não só dos negros ou do movimento negro. $\mathrm{E}$ a nossa ação como educadores e educadoras, do ensino fundamental à Universidade, é de fundamental importância para a construção de uma sociedade mais justa e democrática, que repudie qualquer tipo de discriminação. (GOMES, 2005, p. 52 apud DE MAIA; DA SILVA SÁ, 2019, p. 12).

Assim, deve-se pensar em práticas que vão além da sala de aula, e considerem a realidade vivenciada pelos alunos, e ainda levar em consideração que essas práticas devem ser contínuas e desencadeadoras de reflexões que efetivem ações reais, por meio de projetos que integrem diferentes instituições, níveis educacionais e grupos sociais.

\subsection{Carência de Materiais Didáticos}

Embora, nossas escolas recebam anualmente um número considerável de materiais didáticos, ainda se deparam com a pouca importância reservada a temática de valorização da cultura africana, sendo maior sua ênfase em livros didáticos do conteúdo de história.

Em síntese, às escolas, atualmente, são atribuídas duas tarefas. A primeira é a responsabilidade de acabar com o modo falso e reduzido de tratar a contribuição dos africanos escravizados e de seus descendentes para a construção da nação brasileira. A segunda é fiscalizar que em seu interior alunos negros deixem de sofrer os continuados atos de racismo de que são vítimas. (DE FÁTIMA BORGES, 2010, p. 6).

Anseia-se pela atuação das escolas partindo de um novo posicionamento. As instituições ainda se deparam com a carência na elaboração de obras que tratem essa temática, enfatizando ações corriqueiras vivenciadas pelas pessoas no seu dia a dia, de forma a possibilitar diálogos e reflexões.

Para (De Fátima Borges, 2010, p. 5) "trazer este universo lúdico e mágico da literatura oral dos povos africanos para as salas de aula é um trabalho que também atende à proposta dos Parâmetros Curriculares Nacionais: debater temas emergentes de nossa sociedade nas escolas brasileiras". Constatou-se que a literatura é pouco explorada, uma vez que a maioria dos autores, por medo de serem mal interpretados, evitam inserir essa temática em suas histórias, mesmo sendo algo tão atual e discutido em diferentes setores da sociedade.

Faz-se necessário explorar essa temática desde a infância, uma vez que essa se configura como tempo de formação dos futuros cidadãos, incluindo os clássicos infantis, que não costumam fazer referência a reis e rainhas negros. (De Fátima Borges, 2010, p. 5) afirma que: “[...] esse momento é de relevância não apenas para a população negra, mas também a todos os brasileiros, uma vez que devem educar-se enquanto cidadãos atuantes no seio da sociedade multicultural e pluriétnica, sendo capazes de construir uma nação democrática". É relevante ousar e produzir mais materiais que possam suprir essa lacuna, muitas vezes na própria 
formação de professores, que até então não se preocupavam em lidar com esse conteúdo.

\subsection{Falta de Investimentos na Formação Continuada}

Constatou-se, por final, a falta de investimento da formação continuada para os educadores.

Em todos os momentos, as ações estão voltadas para formação continuada dos professores no que se refere ao cumprimento da lei para a devida valorização da raça negra, com o objetivo de trazer e ampliar o referencial afirmativo para incentivar a construção da identidade negra e contribuir para a elevação da autoestima dos(as) alunos(as) e professores(as) negros(as) da escola. (JESUS, 2015, p. 8).

Deve-se pensar em ações que atendam a necessidade da formação continuada dos professores e ao trabalho de valores com os alunos, consequentemente haverá uma melhoria no que diz respeito à autoestima das pessoas da comunidade escolar que se identificam como negros. A participação de um número maior de professores em cursos de aperfeiçoamento docente com essa temática ainda é um desafio, uma vez que não há muito incentivos por parte das próprias instituições em dispensar seus professores do trabalho para vivenciarem esses momentos de formação.

\begin{abstract}
Trabalhar a formação continuada de professores e gestores de modo a promover a sensibilização para a gestão do currículo na perspectiva das identidades plurais envolvidas nos espaços educacionais e no seu caráter híbrido, contingente e plural, pode representar espaço/tempo discursivo central para a promoção de uma educação valorizadora da diversidade cultural e promotora do sucesso escolar. (CANEN; XAVIER, 2012, p. 311).
\end{abstract}

Nessa perspectiva a formação continuada assume um papel no mínimo relevante no âmbito escolar com consequências notáveis nas práticas educacionais vivenciadas diariamente, tanto por professores e gestores, quanto por alunos.
Nota-se a real necessidade de uma intervenção pautada na reflexão sobre a implementação das leis $10.639 / 03$ e 11.645/08. Essa etapa, de teorização condicionou, através de fundamentação teórica, o levantamento de algumas hipóteses de solução em consonância com o problema detectado no presente estudo.

\section{HIPÓTESES DE SOLUÇÃO}

Analisando tópicos explanados na teorização, efetuada por meio de pesquisas a artigos científicos pré-selecionados, foi possível pontuar algumas possibilidades agravantes à solução dos problemas levantados:

- Fortalecer a parceria com as famílias e comunidade escolar, de tal forma que a participação seja produtiva e positiva, frente à implementação das leis;

- Promoção de uma feira cultural para aquisição de livros que tratem da temática em questão, tratando da cultura africana, afro-brasileira e indígena;

- Criar, com a participação de todo corpo docente, estratégias pedagógicas para a efetivação e cumprimento das Leis $10.639 / 03$ e $11.645 / 08$;

- Realizar encontros pautados principalmente na reflexão sobre a ação, para efetivar-se a formação continuada dos educadores.

As hipóteses de solução apresentadas são viáveis quanto à solução dos problemas apresentados considerando o aspecto e embasamento teórico utilizado no seu levantamento.

\section{POSSÍVEL APLICAÇÃO À REALIDADE}

Diante da situação que o mundo enfrenta nos tempos de pandemia do Corona vírus (COVID-19), última etapa proposta pela metodologia do Arco de Maguerez, a aplicação a realidade, não acontecerá conforme é previsto de forma presencial, porém apresentam-se aqui algumas propostas para as intervenções, caso o cenário epidemiológico fosse outro. 
Das hipóteses de solução apresentadas nesta pesquisa, sugere-se uma proposta de trabalho que envolva todo o corpo escolar, as famílias e comunidade para compreensão e cumprimento das Leis $10.639 / 03$ e $11.645 / 08$, no que tange a aprendizagem dos alunos frente a cultura indígena, africana e afro-brasileira.

Assim, propõe-se a realização de uma feira cultural, promovida pela escola com a ajuda dos alunos, pais e comunidade para aquisições de livros que ajudem no trabalho da temática apresentada no projeto pautado. Com isso, espera-se, além do engajamento da escola, pais, alunos e comunidade, que seja despertado o olhar da equipe pedagógica quanto à necessidade de alinhar educação e realidade da comunidade local, tendo por consequência a busca constante de melhoramento das práticas pedagógicas por meio da formação continuada.

Durante a realização da feira, os pais, auxiliados pelos professores, serão responsáveis em promover atividades com os alunos que desenvolvam conhecimentos e aprendizagens significativas sobre a cultura indígena, africana e afro-brasileira, desse modo todos conseguem compreender culturas tão ricas, e que merecem total respeito de uma sociedade que pouco compreende tamanha riqueza que esses povos trazem consigo e em suas histórias.

É bastante relevante que, para a concretização da proposta, a escola tenha uma gestão democrática, envolvendo os responsáveis e a comunidade nas decisões. Por isso, o momento da feira é também um momento de troca de conhecimento e até mesmo de debates sobre o que propõe as Leis $10.639 / 03$ e 11.645/08, deixando as famílias cientes da sua importância e do cumprimento dentro da instituição, tendo como objetivo a transformação social e cultural da escola e comunidade. Os envolvidos terão a oportunidade de aprender que a potencialidade da aprendizagem está na interação, quanto mais heterogêneo for o grupo com o qual se relacionam, maiores serão as possibilidades de aprendizagem.

\section{CONSIDERAÇÕES FINAIS}

Considera-se a importância e a grandiosidade do tema que foi abordado no estudo apresentado, o qual teve a realização de todo processo executado de forma remota, devido ao distanciamento social nos tempos de pandemia do coronavírus (COVID19). A temática direcionada pelas Leis 10.639/03 e 11.645/08 é extensa e tem prioridade para ser executada em sala de aula, pois quando compreendida e abordada de forma correta no contexto da aprendizagem e compreensão dos alunos, professores e comunidade, reforçam o respeito à uma cultura tão rica e importante para a sociedade.

A compreensão da cultura indígena e africana, possibilita que seja efetivo o respeito e a igualdade que esses povos lutam para conquistar, e que essa luta seja universal e não apenas dos que são atingidos pela dolorosa injustiça existente.

Pesquisar sobre as Leis 10.639/03 e 11.645/08 foi, para os autores do estudo, um momento enriquecedor, pois agregou muito para o entendimento de algo que ainda não haviam se aprofundado. Sobre uma possível aplicação à realidade, foi grande o desejo em poder realizá-la de forma presencial, pois seria o ápice da pesquisa ao ter essa ajuda coletiva de pais, alunos, professores e escola de uma ação voltada às culturas. Avalia-se que foi uma pesquisa bem planejada, fundamentada em embasamentos teóricos que contribuiu para que todas as informações relatadas não sejam meramente achismo, mas sim um conjunto de conteúdos e possíveis práticas que vão ao encontro com informações necessárias inerentes ao ambiente escolar.

Registra-se, por fim, os agradecimentos pelo apoio de todos os envolvidos, aos orientadores, os professores que aceitaram receber e participar respondendo o questionário, de cada autor que concebeu esse estudo que não mediram esforços para efetuar pesquisas e buscas de informações. Estendem-se os agradecimentos às instituições, que, mesmo em tempo de pandemia, não interromperam o ensino e a aprendizagem de seus discentes, confirmando que é nas dificuldades que as transformações acontecem, e consequentemente rompem-se os casulos do medo para um voo de grandes conquistas.

\section{REFERÊNCIAS}

BELO HORIZONTE. Proposições Curriculares para Educação Infantil: Desafios da Formação. Ana 
Cláudia Figueiredo Brasil Silva Melo (Org)- Belo Horizonte: SMED, 2016. 190p.

CANEN, Ana; XAVIER, GP de M. Gestão do currículo para a diversidade cultural: discursos circulantes em um curso de formação continuada de professores e gestores. Currículo sem fronteiras, v. 12, n. 2, p. 306-325, 2012.

COELHO, Marciele Nazaré; CONSTANTINO, Francisca de Lima; MOREIRA, Raquel. Diálogo, igualdade e diversidade: uma tríade para o respeito às diferenças na escola. XVI Encontro Nacional de Didática e Práticas de Ensino (Endipe). Campinas: Unicamp, 2012.

DE FÁTIMA BORGES, Elisabeth Maria. Inclusão da história e da cultura afro-brasileira e indígena nos currículos da educação básica e superior: momento histórico ímpar.

DE MAIA, Luísa Carla Fontoura; DA SILVA SÁ, Janaína. Estratégias pedagógicas para a abordagem da temática racial.

FORTUNATO, Ivan. Olhos azuis, ou as leis 10.639/03 e 11.645/08 na prática. Revista Espaço Acadêmico, v. 13, n. 152, p. 49-55, 2014.

JESUS, Lori Hack De. A História e a Cultura Africana, Afro-Brasileira e Indígena nas Escolas: A Implementação das Leis 10.639/03 e 11.645/08.

Revista de Educação do Vale do Arinos-RELVA, v. 2, n. 2, 2015.

MEC. Conselho Nacional De Educação Conselho Pleno Institui Diretrizes Curriculares Nacionais para a Educação das Relações Étnico Raciais e para o Ensino de História e Cultura Afro-Brasileira e Africana. Disponível em: http://portal.mec.gov.br/cne/arquivos/pdf/res012 004.pdf. Acesso em: 25 mai. 2020.

PEREIRA, Júnia Sales. Diálogos sobre o Exercício da Docência-recepção das leis 10.639/03 e

11.645/08. Educação \& Realidade, v. 36, n. 1, p. 147-172, 2011.

PREFEITURA DE BELO HORIZONTE, Secretaria Municipal de educação. Desafios da Formação Proposições Curriculares da Educação Infantil. Volume 1 - Fundamentos. Belo Horizonte, 2016.
RESENDE, Tânia de Freitas; SILVA, Gisele Ferreira da. A relação família-escola na legislação educacional brasileira (1988-2014). Ensaio: Avaliação e políticas públicas em educação, v. 24, p. 30-58, 2016.

RICARDO, Fany et al. Povos indígenas no Brasil (2001/2005). São Paulo: Instituto Socioambiental, 2006.

ROCHA, Aristeu Castilhos da; SANTOS, Julio Ricardo Quevedo dos; HILLIG, Silvana Grunewaldt. Os percalços de uma Educação Inclusiva: $O$ ensino de História e Cultura Afro brasileira e Sul Riograndense. In: SANTOS, Julio Ricardo Quevedo dos; ROCHA, Aristeu Castilhos da. Africanidades: reflexões afro sul brasileiras. Porto Alegre: Martins Livreiro - Editor, 2016.

SILVA, Edson. Povos Indígenas: História, Culturas E O Ensino A Partir Da Lei 11.645. Publicado in www.revistahistorien.com revista Historien UPE/Petrolina, v. 7, p. 39-49, 2012.

XAVIER, J. T. P.; XAVIER, P. A. M. A invenção e a reinvenção do estereótipo dos afrodescendentes: o papel da ciência, dos cientistas e dos meios de comunicação na formação e articulação do discurso da intolerância. In: KUNSCH, M. M. K.; FISCHMANN, R. (Org.) Mídia e tolerância: a ciência construindo caminhos de liberdade. São Paulo: Editora da USP, 2002. 